\title{
Chapter 12 \\ Personal Leadership: How to Change What Cannot Be Changed: A Response to Wesley Wildman's Out with the Old, In with the New?
}

\author{
Joke van Saane
}

\begin{abstract}
In agreement with Wildman's statement about the structural failures in human functioning caused by individualism and cognitive errors, a new concept is introduced. This is needed because of the risk of generalizing with easy solutions, in so doing neglecting the basic human drives of self-enhancement, connectedness, and mastery. It is better that we acknowledge our individualism and failing cognitions, because this acknowledgment creates room for change. Here, the concept of personal leadership is introduced. Change can start with ourselves as the real game changers. The opportunities for personal leadership are based upon spirituality and spiritual concepts: self-knowledge, self-confidence, norms and values, openness, learning, and imagination.

It is an honor for me to respond to Professor Wildman's argument elsewhere in this book. Under an intriguing chapter title, he offers an even more intriguing idea.

Very roughly summarized, Wildman notes that there are two general biases in the human condition. According to Wildman, you could say that people make at least two structural errors: he shows that people are constantly driven by individualism and that people constantly make cognitive errors. And not just a bit, the illustration of the Cognitive Bias Codex is really discouraging. How do we ever think we can produce reasonable thought?

According to Wildman, these two structural errors are to blame for the fact that it is extremely difficult to change humanity. Change, however, is really needed. Wildman quite rightly refers to the enormous socio-economic problems in Western societies, the global climate threat and the unjustified inequality between people around the globe. Our tendency to individualism and the persistent cognitive errors prevent us from finding fundamental solutions for these huge problems. We cannot jump over our own shadow; we cannot manage to let the public interest prevail over our own; not even if that public interest is under such pressure that there are risks to
\end{abstract}

J. van Saane $(\bowtie)$

University of Humanistic Studies, Utrecht, The Netherlands

e-mail: J.vanSaane@UvH.nl 
personal survival. Individualism falls short when it comes to solving complex global problems, individuals simply do not overlook them.

Wildman proposes two possible solutions to overcome this impasse, fundamentally caused by the human condition wherein we are cognitive and individual organisms. He looks at philosophy for the first type of solution. In his view, philosophers can help with the development of new concepts. Conceptual reconstruction, for example, reveals that the biological and cultural dimensions of human life are strongly interrelated and cannot be dismantled. Homo economicus and Homo amans are not available separately; as humans we cannot choose to be one or the other. We can, however, choose what we give priority to in our self-understanding as persons. Reflection on the frames and the concepts can reinforce this self-understanding and lead to more conscious forms of desired behavior.

And Wildman shows, very convincingly in my opinion, that no completely new fields of research are needed in order to arrive at that conceptual reconstruction. To be able to give relationality a place in the concept of humanity in addition to individualism, we only have to take seriously what is happening in research areas outside of philosophy. Chemistry, physics, geology, evolutionary biology, biochemistry, neurological psychology, etc. prove that people are not only individualistic organisms, but (also) fundamentally relational: to each other, to the world, to ourselves. Wildman shows that we are related at a fundamental level, because we are all human beings, sharing the same evolutionary processes and physical laws. So, it is rich and multi-dimensional relationality that proves to be fundamental for humanity, not individualism.

In other words, there seems to be a great deal of consensus on the modern secular interpretation of humanity in which relationality is central. Western hyperindividualism must therefore be seen as an extreme and ultimately unsustainable social construction of human nature. Although dominant, hyper-individualism is, according to Wildman, fundamentally implausible in the light of the research results in other domains, as a result of which individualism is corrected by relationality. The spiritual translation of relationality can be found in the domain of metaphysics, in which there is such a thing as selfless love, love as agape and karuna. Deploying this love can lead to a reduction in (the effects of) individualism. I like the translation of the corrective into a spiritual virtue, because spiritual virtues imply the opportunity to learn, to practice, and to share. If the corrective was only philosophical or cognitive, one dimension would be replaced by another one. But by adding the notion of spirituality Wildman really opens up something new, something healing.

Wildman proposes something similar for the bias of cognitive errors. He shows that increasing self-awareness contributes to reducing the impact of cognitive errors. People can learn, and people can consciously avoid certain pitfalls. The corrective of self-awareness is translated spiritually by Wildman as wisdom, wisdom in the form of knowledge and humility. This wisdom, just like love, is a spiritual virtue and can also be learned, practiced, and emphatically developed. Putting it this way, by bringing in metaphysical concepts Wildman opens up - without reflecting on it - the possibility of growth and change. 
Although this is already an impressive reconstruction of concepts, Wildman acknowledges that this will not be enough to bring about real change in society, given the complexity of the problems humanity is facing worldwide, and in particular in the West. For change to happen you need a philosophical basis, but especially to have that in partnership with other actors. In Wildman's words, some reality must be added to philosophy. Education, religion, politics, and marketing are important areas for making the change happen. Within these areas, philosophers must join forces with other professionals, and arrive at concrete actions together, and this is what will really make a difference. I am not quite sure if advertising campaigns or explicit political rhetoric - examples sketched out in Wildman's chapter - will actually help, but I really appreciate the idea and especially the optimism contained in this idea.

Up to this point, we can say "amen" to Wildman's argument. His reflection about the shortage of solutions to real complex global problems is based upon a solid package of both empirical and theoretical research. But I am not fully convinced that this combination of philosophical reconstruction and the development of broad partnerships will actually lead to the real change we so desperately need in our contemporary societies.

As a matter of fact, the separate elements that need to be in place for this reconstruction of reasoning are so massive and unchangeable that reconstruction and partnerships will not be sufficient to bring about change.

To start with, I would like to emphasize how deeply rooted the failures in human structures are. After all, individualism and cognitive errors are fundamental parts of the human condition. Within psychology, many research studies (e.g. Smith and Mackie 2007'; Mullen and Riordan 1988; Kaplan and Wilke 2001) show that human beings are characterized by a few basic drives that are very important for our functioning, both on the levels of cognition and emotion as well as on the level of behavior. I summarize these basic human drives here as self-enhancement (or the self-serving bias), connectedness, and mastery, explicitly in this order (see van Saane 2010). Self-enhancement is safeguarding self-interest, working on a positive self-image, and avoiding negative experiences about the self. The individualism that Wildman observes can be seen as a result of this self-enhancement. Besides, individualism - contrary to Wildman's suggestion - is not equivalent to pure selfconcern and selfishness. It is the fundamental urge to live and survive. This basic drive of self-enhancement can be mirrored in the fear of death, the fear of one's own mortality. This fundamental human drive can be understood as the ultimate reason behind human inclination to cognitive errors.

At the same time however, just as fundamentally, people are driven by the need for connectedness, or, in other words and expressed by, the fear of isolation. People are relational beings who care firstly about themselves, but also constantly seek to connect with others. Fear of isolation and fear of loneliness are strong incentives for

\footnotetext{
${ }^{1}$ The textbook of Smith and Mackie (2007) offers a thorough overview of the state of art in cognitive social psychology. The three motivational principles form one of the basic lines of argument in this overview (cf. Smith and Mackie 2007, p. 17).
} 
behavior. This very fundamental basic human drive opens up relationality as characteristic of humanity, not as a corrective for individualism or self-enhancement, but as a fundamental keystone of our psychological system.

And the strive for mastery can be added to these two basic drives of selfenhancement and connectedness. Human beings are self-concerned and they are connected. These drives are influenced by the continuous search for certainty and predictability. People have a hard time dealing with uncertainty, with not knowing what to expect. If this third drive for mastery is put under pressure, the first drive of self-enhancement becomes more dominant as a strategy for coping with unpredictability and fear. From this perspective of the basic need for mastery, it is therefore very understandable that people are overwhelmed by the complexity of contemporary global problems such as socio-economic relations and climate issues. Delving into these problems leads, by definition, to uncertainty and unpredictability for people. This tempts us to ignore or simplify these problems. And in turn, it tempts us to prioritize the drive for self-enhancement (individualism) and the drive for connectedness (withdrawing into our own social group).

I am not so optimistic about our ability to change or correct these fundamental tendencies. There is plenty of research (e.g. Alicke and Sedikides 2010; Smith and Mackie 2007) showing that these basic drives are rooted in biological, evolutionary, and neurological mechanisms that we should regard as given, rather than as accidental characteristics.

This persistence of human characteristics and basic psychological drives will also play a role in those strategic and practical partnerships proposed by Wildman. We remain human beings, even if we come from other areas such as education or politics, and even if we are willing to cooperate. We always, and inevitably, will continue to put our own individual interests first. And if there is a lot of uncertainty to be reduced, these mechanisms of self-enhancement or individualism and withdrawing into our own community to feed the drive for connectedness will only become more dominant in our cognitive system, both on a conscious as on an unconscious level.

So, the old cannot simply be replaced by something new, no matter how philosophically brilliant the new concepts may be. People are, so to speak, trapped in their own human condition. The same could be said for the problems that confront humanity. After all, these problems are in part the result of unashamed and unimpeded submission to basic individual needs. All these individual tendencies towards self-interest naturally exclude each other and are the building blocks on which the self-destructive capacity of humanity develops. Indulging in individual interest ultimately harms humanity as a whole. The human shortage is a reflection of human capacity, and this means that human shortage is just as firm and unavoidable. The complexity of the global problems does not help. They are monsters that have grown completely over our heads and now threaten to crush us.

I would not look for the potential for change so much through philosophical reconstructions, followed by strategic and practical partnerships, but rather in the real acceptance of this fundamental human condition. Only if we dare to face human reality, does room appear to develop strategies that might possibly mitigate the 
consequences of humanity's failures. No unfounded optimism or naivety, but realism and a mature attitude of self-reflection.

In my opinion, we can introduce the concept of personal leadership here. To do so, let us dig a bit deeper into the discipline of spirituality. Wildman translates the correctives of individualism and cognitive errors (respectively relationality and selfawareness) into the spiritual concepts of love as agape and karuna and the virtue of wisdom. In my opinion however, this is only a start: more discussion and more thorough thinking about spirituality is needed if we are to arrive at sustainable change and transformation.

For the definition of spirituality, I follow the philosopher Roothaan, (cf. van Saane 2019) who defines spirituality as an attitude of openness, attention, and consciousness (Roothaan 2007, p. 65). This attitude may be based on a philosophical or religious worldview, but that need not be the case. Spirituality can also be rooted in a more secular worldview.

Defined in this way, spirituality can be seen as an ongoing process of seeking meaning, with an open attitude, a focus on sustainability and credibility, rooted in self-knowledge and in the desire for growth and development. At its core, spirituality is about this fundamental search for meaning. And it is important to realize, spirituality is also always connected with morality, with norms and values that set the public interest against the satisfaction of one's own need.

To see how spirituality can help in bridging the gap between structural human failures such as individualism and cognitive errors and the need to find sustainable solutions for complex global problems, I like to underscore the fact that within spiritual traditions, truth can only be personal truth (van Saane 2019). Abstract general truth can be nice to hear, or to study, but will be powerless when we are seeking real change. Then, we need personal truth. This truth should not only be found, but also constructed by the seeker who is flexible and open in nature. Personal truth offers a renewed perspective on someone's life and world. Truth must be involved constantly in one's own life and in one's own context. This is what we learn in studying spirituality: abstract truth, even if it is spiritual or religious i.e. absolute truth, as such, is meaningless. Developing personal truth is a process of construction and connection that is, in principle, infinite: one never reaches the point that the search can be stopped. Finding personal truth is an ongoing journey.

It is not so easy to develop personal truth - we know this from different spiritual traditions. It takes a whole process of reflection, meditation, discussion, and practice. In the first place, we need a rather high level of self-knowledge. We need to know our own strengths and weaknesses, where the pitfalls lie and how our personal experiences influence behavior. Lack of self-knowledge will result in lack of knowledge of the other; knowing yourself leads to knowing the other. However, selfknowledge is not the only contribution from spirituality. Secondly, spirituality makes clear that we benefit from self-confidence. Self-confidence is self-knowledge in combination with acceptance of yourself. Within spiritual traditions this is an important element, because self-confidence is part of the perception of yourself through the eyes of the other, and through the eyes of God. The perspective of God as an absolute reality also leads to a third element of spirituality worthy of taking 
into consideration here: norms and values. The preference for individual interest rather than the general interest of humanity as a whole can easily result in immoral behavior. In almost all spiritual traditions it is a recurrent refrain: do good, take care of the other person, put the other person before yourself. We certainly need openness to new experiences and the capability of learning if we are to meet these spiritual standards. Learning is the connecting and fundamental concept here. The core of learning is in itself a process of change and transformation. Learning is not easy, it requires participation, hospitality, willingness to question assumptions. Transformation costs time and effort, change provokes resistance. Developing personal truth, learning about yourself and the world around you, is not at all easy.

The last important element of spirituality that I want to examine as a building block for inspiration and change is imagination. In Wildman's approach, imagination appears at the end, in the form of computer simulation games as virtual learning labs, a space for trying things out. I think imagination is more than that, and deserves a more fundamental role here. Imagination enables one to rise above the everyday perspective, to imagine the apparently impossible, and to be capable of acting from an ideal and visionary perspective. Within spirituality, we know that imagination flourishes from irrational forms of knowledge; imagination can involve creative and intuitive thinking (Van Saane 2012, 2014; Verstraeten 2003).

Reflection on these spiritual dimensions is required - obviously far more thoroughly carried out than in this chapter - on self-knowledge, self-confidence, norms and values, openness, learning, and imagination, for example, when we are thinking about a transformation from Homo economicus to Homo amans, something which is very much needed in our times. For me, this reflection and these forms of learning are part of a form of leadership, known as personal leadership (van Saane 2015, 2017). Personal leadership can be defined as knowing yourself, controlling yourself, your personal environment, and your life as a whole.

In my opinion, personal leadership is the gateway to real transformation. It is inextricably linked to a mature attitude to life, leaving room for responsibility and sensitivity, for resilience. By learning to accept oneself, by establishing good relationships with others, by getting the best out of yourself, by giving meaning to your life, and by maintaining a certain autonomy, regardless of the context, you can use your full potential, on an individual and social level (Ruijters et al. 2015; Ryff and Singer 2013; Ryff 2014).

So, in conclusion, I agree with Wildman about the inevitability of the structural errors of man as subject. I do not agree about the possibility of correctives for that. We are better to acknowledge our individualism and failing cognitions, because this acknowledgment creates room for change. Hoping for correction erects a barrier to change. If that happens, we will be disappointed, time and again.

I am not saying that there is no hope for change. I am not stepping back from responsibility. I do not think that we can never tell others to change their behavior. Yes, we can. But we have to start with ourselves. We need personal leadership. Be realistic, embrace the human shortage and look for ways to connect people with themselves and with others. Look for ways to make people at peace with loss and sorrow. Look for ways not to lose courage but to tackle the problems. Don't look at 
the other, or the system, or the science. Look, and start, with yourself, by pursuing personal leadership. Don't complain, don't be fatalistic, don't be naïve or too optimistic. Just start with yourself, do something good, and be an inspiration for others.

Where I do want to join with Wildman is in his plea for imagination to have a role. He outlines the possibilities of computer simulation in a game context. This seems to me to be similar to other forms of artistic expression. Within the psychology of religion it is widely understood: creativity is a means for thinking of the impossible as possible, or even to experience it, to give space to personal needs and desires, to overcome paradoxes. Computer simulation, artistic expressions, rituals, narrativity, spiritual exercises in love and wisdom: we should cherish them all and let them grow, because these provide the opportunities for humanity's future.

In its psychological function, imagination is similar to therapy and to religion. Imagination, artistic expression, therapy, and religion enable people to accept reality, and the brokenness of human beings. Imagination can bridge the gap between the shortcomings of human psychology and the enormous threats from outside. Imagination does not lead to easy solutions, or quick fixes, but by imagination we can literally see potential solutions. Imagination provides for a try-out, virtually. We need imagination to come up with real and new solutions, to get beyond human limitation. If we focus on the development of personal leadership and mature attitudes towards mankind, change can happen. It can start within imagination, and be continued in reality.

In summary, I fully agree with Wildman about the structural failures in human functioning. And yes, individualism and cognitive errors are important examples of these failures. I also agree about the necessity of a multi-disciplinary approach, combining philosophy with actors in different domains. The risk of this approach, the generalization of easy solutions, can be overcome by focusing on personal leadership. Change does not start with the other, nor with the world around us, but with ourselves. We, as individuals, are the real game changers. And we can do it, because with personal leadership we can base our approach on spirituality and spiritual concepts, well-proven for hundreds of years. Nothing new, nothing unreachable, but practical and hopeful.

\section{References}

Alicke, M.D., and C. Sedikides. 2010. Handbook of Self-Enhancement and Self-Protection. New York: Guilford Press.

Kaplan, M.F., and H. Wilke. 2001. Cognitive and Social Motivation in Group Decision Making. In The Social Mind: Cognitive and Motivational Aspects of Interpersonal Behavior, ed. J.P. Forgas and K.D. Williams, 406-428. New York: Cambridge University Press.

Mullen, B., and C.A. Riordan. 1988. Self-serving Attributions for Performance in Naturalistic Settings: A Meta-analytic Review. Journal of Applied Social Psychology 18: 3-22.

Roothaan, A. 2007. Spiritualiteit begrijpen: Een filosofische inleiding. Amsterdam: Boom.

Ruijters, M.C.P., et al. 2015. Je Binnenste Buiten: Over professionele identiteit in organisaties. Deventer: Vakmedianet. 
Ryff, C.D. 2014. Psychological Well-being Revisited: Advances in the Science and Practice of Eudaimonia. Psychotherapy and Psychosomatics 83 (1): 10-28.

Ryff, C.D., and B.H. Singer. 2013. Know Thyself and Become what you Are: A Eudaimonic Approach to Psychological Well-being. In The Exploration of Happiness, ed. A. Della Fave, 97-116. Dordrecht: Springer.

Smith, E.R., and D.M. Mackie. ${ }^{32007 . ~ S o c i a l ~ P s y c h o l o g y . ~ N e w ~ Y o r k: ~ P s y c h o l o g y ~ P r e s s . ~}$

van Saane, J. 2010. Religie is zo gek nog niet: Een introductie in de godsdienstpsychologie.

Utrecht: Ten Have.

- 2012. Geloofwaardig leiderschap. Zoetermeer: Boekencentrum.

2014. Spirituality and the Psychology of Leadership Credibility: An Analysis from the

Psychology of Religion. In Leadership, Spirituality and Innovation, ed. J. Barentsen and P. Nullens, 41-56. Leuven: Peeters.

- 2015. Geloofwaardig onderwijs: Van kennis naar persoonlijk leiderschap. Inaugural address. Vrije Universiteit Amsterdam.

- 2017. From Cognitive Science to Personal Leadership: The Role of Religion and Personal

Life Orientation in Curriculum Development Processes within the Domain of Religious

Studies. In Religion and Higher Education in Europe and North America, ed. K. Aune and J. Stevenson, 181-190. London: Routledge.

- 2019. Personal Leadership as Form of Spirituality. In Leading in a VUCA World:

Integrating Leadership, Discernment and Spirituality, ed. J. Kok and S.C. van den Heuvel, 43-58. Dordrecht: Springer.

Verstraeten, J. 2003. Leiderschap met hart en ziel: Spiritualiteit als weg naar oorspronkelijkheid.

Tielt: Lannoo.

Open Access This chapter is licensed under the terms of the Creative Commons Attribution 4.0 International License (http://creativecommons.org/licenses/by/4.0/), which permits use, sharing, adaptation, distribution and reproduction in any medium or format, as long as you give appropriate credit to the original author(s) and the source, provide a link to the Creative Commons license and indicate if changes were made.

The images or other third party material in this chapter are included in the chapter's Creative Commons license, unless indicated otherwise in a credit line to the material. If material is not included in the chapter's Creative Commons license and your intended use is not permitted by statutory regulation or exceeds the permitted use, you will need to obtain permission directly from the copyright holder.

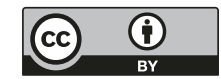

